\title{
'Panacea' for all cancers banned in Italy
}

A glycoprotein of unknown structure extracted from goat liver and code-named UK101 has been banned by Italian authorities who fear that the public is being duped by claims that the drug cures cancer. UK101 has been given by injection to hundreds of cancer patients despite any proof of clinical efficacy. Now Italian officials are sponsoring a full scientific investigation.

The affair has caused an unprecedented public row among the medical community, with one side claiming that Alberto Bartorelli, an immunologist from the G. Sisini Institute of the University of Milan, who developed UK101 and has financial interests in the compound, has tried to bypass standard drug registration procedures, and Bartorelli, claiming that he has been unfairly treated by his peers.

The controversy surrounding UK101 has also raised questions about the lack of clear rules governing the compassionate use of drugs in Italy, which are now to be tightened. In the early 1990s, Bartorelli applied to the regional health authority of Lombardi in northern Italy, where he had already been administering the drug to consenting patients since 1988 , requesting formal approval for its use on a compassionate basis. The authority's committee for human experimentation turned down the request because of lack of appropriate documentation on patient selection, clinical protocol and assessment criteria.

But Bartorelli was more successful in Rome, where in 1993 he received the blessing of Italy's former Health Minister Mariapia Garavaglia to provide the drug to patients with advanced cancer resistant to other forms of drug treatment and radiotherapy. The grounds for approval are not clear, and expert advice was not formally sought.

The drug hit the headlines after Bartorelli presented early clinical results of UK101, which is an immunostimulant, at the 12th International Conference on Human Tumor Markers in New York in June. It precipitated a flood of requests, mostly from cancer patients and their relatives, for treatment.

As a result, the current Health Minister Elio Guzzanti set up a committee, chaired by Leonardo Santi from the National Institute of Cancer Research in Genoa, to assess the situation. The institute also immediately set up a hot line to deal with calls from the public. Three telephone lines, permanently staffed by doctors, continue to receive hundreds of calls per day; 15 calls were received every hour in July after news of UK101 broke.

After examining the clinical records of hundreds of cancer patients treated with UK101 since 1988, Santi's committee concluded that there is insufficient evidence to justify widespread compassionate use of the drug. Clinical results collated so far, it stated, were not interpretable because no standard treatment protocol had been established. Moreover, says Santi, in no

\section{It is hard to believe}

that a drug could be

\section{injected into humans}

without proper control, in

$$
\text { the 1990s, in Italy. }
$$

case was there a documented reduction in tumour size, although subjective improvement in pain relief, as assessed by the patients, was noted. No significant toxicity was reported.

The committee specifically criticized the lack of full viral testing of the compound. (This is a general requirement in all countries for injection of biological extracts into humans.) Bartorelli counters such criticism by saying that the technical conditions of the extraction process would in any case not permit survival of viruses.

On the basis of the committee's recommendations, Guzzanti suspended the use of the drug in new patients. The continued treatment of patients already receiving UK101 was allowed, until the committee has completed its deliberations. The committee further recommended that UK101 be considered for formal clinical trials, provided that the manufacturer presents appropriate certification regarding viral contamination and a proper clinical protocol, including dose recommendations, indications of centres where testing should be carried out and appropriate assessment criteria of the drug's efficacy.

The patent for UK101 is held by a small company in Milan called Zetesis, of which Bartorelli is one of only four shareholders (two others are Fiat and Mediobanca,
Italy's largest investment bank). The company granted an exclusive licence to the Milan-based pharmaceutical company Sicor in summer 1994 to market the compound, which is manufactured by one of its subsidiaries, Zanoni.

Sicor, which sponsors research on UK101 carried out by Bartorelli and his co-workers at the University of Milan and the University of Turin, claims to have done no promotional work on the drug and is embarrassed to find itself at the centre of the row. Together with Bartorelli, the company is planning to provide the documentation requested by the committee and to submit a formal proposal for a clinical trial.

Many clinical scientists in Italy have been outraged by the affair. Gianni Tognoni, a clinical pharmacologist at the Mario Negri Institute in Milan, finds it "hard to believe that a drug could be injected into humans without proper control, in the 1990s, in Italy." Tognoni feels that the compound has received undue attention. "There was never any urgency for the compound to be considered for special use," he says, and on this basis he opposed the setting up of Santi's committee.

Gianni Bonadonna, who is chairman of the department of cancer medicine at the Milan Cancer Institute, is also an outspoken opponent of the drug, but believes that the committee is the only practical way of dealing with what he considers to be public hysteria. Bonadonna sees an analogy with the 'laetrile affair'. This cyanide-containing extract of apricot kernels was introduced into the United States from Mexico in the 1980 s to treat terminally ill cancer patients whose unreasonable expectations of its efficacy were fanned by the media. Eventually, public pressure forced the US Food and Drug Administration to approve a controlled clinical trial. Although the trial proved negative, demands for compassionate treatment with laetrile continued.

"It is similar," says Bonadonna. A proper trial is necessary, he argues, "because if you are too dogmatic you lose the battle; you cannot kill all the quacks, so you have to demonstrate in a cold way that it does not work." Even then, he notes, as the laetrile trial shows, it is hard to shake the blind faith of the terminally ill.

Alison ABbott Munich 